\title{
A DEA-BASED MALMQUIST PRODUCTIVITY INDEX APPROACH IN ASSESSING ROAD SAFETY PERFORMANCE
}

\author{
YONGJUN SHEN ${ }^{1}$ \\ ${ }^{1}$ Transportation Research Institute - Hasselt University \\ Wetenschapspark 5 bus 6, 3590 Diepenbeek, Belgium \\ ELKE HERMANS $^{1}$, DA RUAN ${ }^{1,2}$, KOEN VANHOOF ${ }^{1}$, TOM BRIJS ${ }^{1}$, GEERT WETS ${ }^{1}$ \\ ${ }^{2}$ Belgian Nuclear Research Centre (SCK·CEN) \\ Boeretang 200, 2400 Mol, Belgium
}

\begin{abstract}
The data envelopment analysis (DEA) based Malmquist productivity index measures the productivity change over time. It can be further decomposed into two components: the change in efficiency and the technical change. In this study, a specific road safety outputoriented DEA-based Malmquist productivity index is introduced to assess the changes in road safety performance of 26 EU countries from 2000 to 2007. The results show a considerable road safety progress in most of the member states during this period. The decomposition into the two components further reveals that the bulk of the improvement was attained through the adoption of new road safety technologies or strategies, i.e., the technical change, rather than through the relatively inefficient countries catching up with those efficient ones, known as the efficiency change.
\end{abstract}

\section{Introduction}

Road traffic injuries and fatalities have been recognized as an important public health issue all over the world. Every year, over 1.2 million people die as a consequence of road crashes and as many as 50 million suffer non-fatal injuries [1]. In most regions of the world, this epidemic is still increasing [2]. Under these circumstances, more and more road safety strategies and programmes have been launched, especially since 2000. In particular, the European Union (EU) has set itself a target of halving the yearly number of road fatalities between 2001 and 2010 [3]. At the target year by now, it is both interesting and necessary for each member state and the EU as a whole to assess its road safety progress in the past few years so as to monitor the effectiveness of implemented programmes. However, simply considering the reduction of the number of fatalities does not reflect the real improvement in road safety since the transport circumstances of a country which can impact on the final outcome also changes every year, such as the degree of participation in traffic. To assess the dynamic road safety progress, this study not only focuses on the development of road fatalities, but also considers information on three common measures of exposure, 
i.e., the number of inhabitants, passenger cars, and passenger-kilometres travelled. Data envelopment analysis (DEA) [4] and the Malmquist productivity index [5] are employed to undertake the assessment from 26 EU countries' data over the period of 2000-2007 [6].

\section{DEA-based Malmquist productivity index}

Data envelopment analysis [4] is a non-parametric linear programming methodology to measure the relative efficiency of a homogeneous set of decision making units (DMUs) on the basis of multiple inputs and multiple outputs. The concept of the Malmquist productivity index was originally introduced by Malmquist [5] as a quantity for analyzing the consumption of inputs. Afterwards, Färe et al. [7] constructed a Malmquist productivity index directly from input and output data using DEA. Specifically, the DEA-based Malmquist productivity index, hereafter referred to as DEA-MI, relies on firstly constructing an efficiency frontier over the whole sample realized by DEA and then computing the distance of individual observations from the frontier. In practice, this DEA-MI has proven to be a good tool for measuring the productivity change of DMUs over time, and has been successfully applied in many fields $[8,9]$.

To describe the method, we consider a set of $n$ DMUs, or the 26 EU countries in which each consuming $m$ different inputs to produce $s$ different outputs. $x_{i j}^{t}, y_{r j}^{t}$ denote the $i$ th input and $r$ th output respectively of the $j$ th DMU at any given point in time $t$. The DEA-MI calculation requires two single-period and two mixed-period measures. The two single-period measures are obtained by solving the basic DEA model. However, as opposed to other research fields such as economics, here we want the output, i.e., the number of road fatalities to be as low as possible based on a given set of inputs. Consequently, an adjusted road safety output-oriented DEA model ${ }^{1}$ is proposed as follows:

$$
\begin{array}{ll} 
& D_{o}^{t}\left(x_{o}^{t}, y_{o}^{t}\right)=\min \theta \\
\text { s.t. } \quad & \sum_{j=1}^{n} x_{i j}^{t} \lambda_{j} \geq x_{i o}^{t}, \quad i=1, \cdots, m \\
& \sum_{j=1}^{n} y_{r j}^{t} \lambda_{j} \leq \theta y_{r o}^{t}, \quad r=1, \cdots, s \\
& \lambda_{j} \geq 0, \quad j=1, \cdots, n
\end{array}
$$

This linear program is computed separately for each DMU, and the subscript, $o$, refers to the DMU whose efficiency is to be evaluated.

\footnotetext{
${ }^{1}$ The model can be deduced from the basic input-oriented DEA model by switching each of the inputs and outputs into the place of the other.
} 
$\theta(0<\theta \leq 1)$ is the uniform proportional reduction in the DMU $\mathrm{D}_{o}$ 's outputs. Its minimum amount is known as the DEA efficiency score for $\mathrm{DMU}_{o}$, which also equals to the distance function of $\mathrm{DMU}_{o}$ in year $t$, i.e., $D_{o}^{t}\left(x_{o}^{t}, y_{o}^{t}\right)$. As a result, if the value of $\theta$ equals to one, then the DMU is efficient and its input-output combination lies on the efficiency frontier. In the case that $\theta<1$, the DMU is inefficient, and it lies inside the frontier. In a similar way, using $t+1$ instead of $t$ for the above model, we obtain the efficiency score of $\mathrm{DMU}_{o}$ in the time period $t+1$, denoted as $D_{o}^{t+1}\left(x_{o}^{t+1}, y_{o}^{t+1}\right)$.

For the mixed-period measures, the first one is defined as $D_{o}^{t}\left(x_{o}^{t+1}, y_{o}^{t+1}\right)$ for $\mathrm{DMU}_{o}$, which is computed as the optimal value resulting from the following linear programming problem:

$$
\begin{array}{ll}
D_{o}^{t}\left(x_{o}^{t+1}, y_{o}^{t+1}\right)=\min \theta & \\
\text { s.t. } \quad & \sum_{j=1}^{n} x_{i j}^{t} \lambda_{j} \geq x_{i o}^{t+1}, \quad i=1, \cdots, m \\
& \sum_{j=1}^{n} y_{r j}^{t} \lambda_{j} \leq \theta y_{r o}^{t+1}, \quad r=1, \cdots, s \\
& \lambda_{j} \geq 0, \quad j=1, \cdots, n
\end{array}
$$

This model compares $\left(x_{o}^{t+1}, y_{o}^{t+1}\right)$ to the frontier at time $t$. Similarly, we can obtain the other mixed-period measure $D_{o}^{t+1}\left(x_{o}^{t}, y_{o}^{t}\right)$, which compares $\left(x_{o}^{t}, y_{o}^{t}\right)$ to the frontier at time $t+1$.

The (output-oriented) DEA-MI, which measures the productivity change of a particular $\mathrm{DMU}_{o}$ at time $t+1$ and $t$, can be expressed as [7]:

$$
M_{o}=\left[\frac{D_{o}^{t}\left(x_{o}^{t+1}, y_{o}^{t+1}\right)}{D_{o}^{t}\left(x_{o}^{t}, y_{o}^{t}\right)} \frac{D_{o}^{t+1}\left(x_{o}^{t+1}, y_{o}^{t+1}\right)}{D_{o}^{t+1}\left(x_{o}^{t}, y_{o}^{t}\right)}\right]^{1 / 2}
$$

$M I_{o}>1$ indicates progress in the total factor productivity of the $\mathrm{DMU}_{o}$ from the period $t$ to $t+1$, while $M I_{o}=1$ and $M I_{o}<1$ means respectively the status quo and decay in productivity.

Moreover, in contrast to conventional production functions or other index approaches, the DEA-MI can be further decomposed into two components, one measuring the change in efficiency and the other measuring the change in the frontier technology. Mathematically, these two components can be measured by the following modification of $M I$ in (3) [7]:

$$
M I_{o}=\frac{D_{o}^{t+1}\left(x_{o}^{t+1}, y_{o}^{t+1}\right)}{D_{o}^{t}\left(x_{o}^{t}, y_{o}^{t}\right)}\left[\frac{D_{o}^{t}\left(x_{o}^{t+1}, y_{o}^{t+1}\right)}{D_{o}^{t+1}\left(x_{o}^{t+1}, y_{o}^{t+1}\right)} \frac{D_{o}^{t}\left(x_{o}^{t}, y_{o}^{t}\right)}{D_{o}^{t+1}\left(x_{o}^{t}, y_{o}^{t}\right)}\right]^{1 / 2}
$$


The first term, i.e., $E F F C H=D_{o}^{t+1}\left(x_{o}^{t+1}, y_{o}^{t+1}\right) / D_{o}^{t}\left(x_{o}^{t}, y_{o}^{t}\right)$ indicates the magnitude of the efficiency change from the period $t$ to $t+1$, which also reflects the capability of a country in catching up with those efficient ones. The second one, i.e., TECHCH $=\left[\frac{D_{o}^{t}\left(x_{o}^{t+1}, y_{o}^{t+1}\right)}{D_{o}^{t+1}\left(x_{o}^{t+1}, y_{o}^{t+1}\right)} \frac{D_{o}^{t}\left(x_{o}^{t}, y_{o}^{t}\right)}{D_{o}^{t+1}\left(x_{o}^{t}, y_{o}^{t}\right)}\right]^{1 / 2}$ measures the shift in the technology frontier between two time periods. From the output-oriented view of road safety performance assessed in this study, an improvement in efficiency occurs when there are decreases in the quantities of output (fatalities) based on a given set of inputs. In contrast to a change in efficiency, technical change occurs through the adoption of new road safety technologies or strategies that reduce the minimum quantities of output given a certain level of inputs. For these two components, values greater than one indicate an improvement in that aspect, while values less than one imply deterioration. In the following section, the DEA-MI is applied to measure the combined effect of efficiency enhancements and technical change in terms of road safety progress in Europe from 2000 onwards meanwhile capturing the separate impact of each effect.

\section{Applications}

Currently, the road safety situation of a country is mostly evaluated in terms of risk, which is defined as the ratio of road safety outcomes and some measure of exposure [10]. In this study, the data about the three common measures of exposure to risk, i.e., the number of inhabitants, passenger cars and passengerkilometres travelled, as well as the number of road fatalities are collected from 2000 to 2007 for the 26 EU countries (the EU-27 except Malta) ${ }^{2}$, which are Austria (AT), Belgium (BE), Bulgaria (BG), Cyprus (CY), Czech Republic (CZ), Denmark (DK), Estonia (EE), Finland (FI), France (FR), Germany (DE), Greece (EL), Hungary (HU), Ireland (IE), Italy (IT), Latvia (LV), Lithuania (LT), Luxembourg (LU), the Netherlands (NL), Romania (RO), Poland (PL), Portugal (PT), Slovakia (SK), Slovenia (SI), Spain (ES), Sweden (SE), and the United Kingdom (UK) [6]. The DEA-MI is then employed to measure the extent to which the countries have improved their road safety during the given period.

Figure 1 indicates the cumulative $M I$ and its decomposition (i.e., $E F F C H$ and TECHCH) from 2000 to 2007 by sequential multiplication of the improvements in each year with 2000 as the index year (equal to one). From the trend of $M I$, the $26 \mathrm{EU}$ countries as a whole exhibits considerable improvement in road safety (over 30\%) during this period, and it is mostly dominated by its technical component. In other words, the main source of this growth is the rapid technical change, which is partially offset through a decrease in efficiency.

\footnotetext{
${ }^{2}$ The initial examination revealed the very distinct nature of the data for Malta and consequently, it
} was decided to eliminate this outlier and consider only 26 EU countries. 


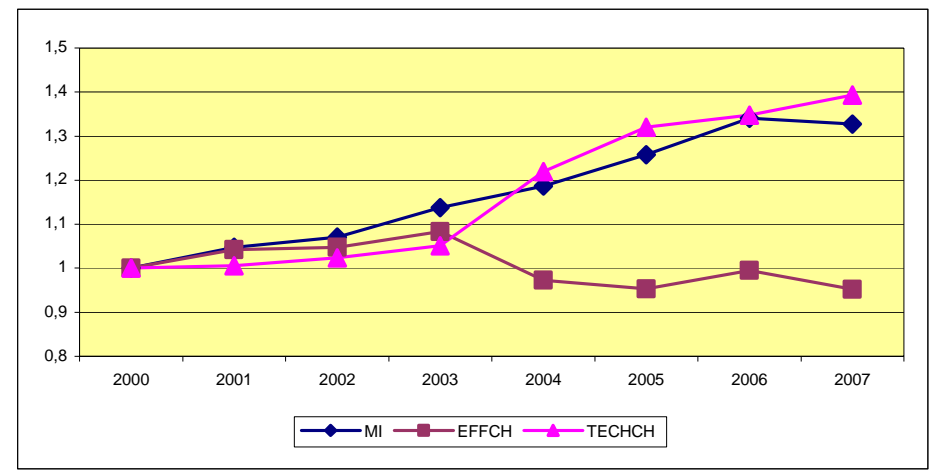

Fig. 1. The evolution in MI, EFFCH and TECHCH during 2000-2007

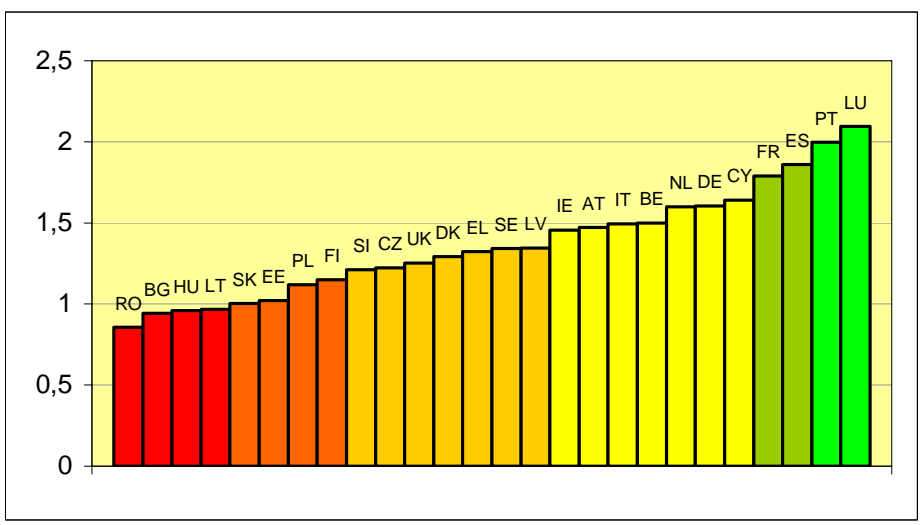

Fig. 2. Overall road safety progress in the $26 \mathrm{EU}$ countries from 2000 to 2007

Moreover, Figure 2 illustrates the overall road safety progress of each of the 26 EU countries during the past eight years. Except for Romania, Bulgaria, Hungary, and Lithuania, which have an overall $M I$ value less than one, all other EU countries improved their road safety performance during the time period. Among others, Luxembourg and Portugal are the two best performers, which have already doubled their road safety performance compared with that in 2000 . It means they have dynamically realized the EU target of halving the yearly number of road fatalities by taking the exposure into account. In addition, Spain and France are the two other countries that are also performing quite well and will possibly catch up with those two best performers within the timescale at the 
current rate of advance. The remaining countries have progressed however to a lesser extent, and thereby great efforts are still needed.

\section{Conclusions}

Using the road safety output-oriented DEA-based Malmquist productivity index, we have assessed the changes in road safety performance of the $26 \mathrm{EU}$ countries from 2000 to 2007 based on their road fatalities and the three measures of exposure. The analysis finds that there was a significant road safety progress in Europe during this period. However, the development in the different countries was unbalanced. Some of them were even declining in terms of the road safety performance. Moreover, the decomposition of the DEA-MI further revealed that the bulk of the improvement was attained through the adoption of new road safety technologies or strategies, rather than through the relatively inefficient countries catching up with those efficient ones.

\section{References}

1. World Health Organization, World report on road traffic injury prevention, Geneva, http://www.who.int/violence_injury_prevention/publications/road_ traffic/world_report/en/ (2004).

2. World Health Organization, World health statistics 2008, Geneva, http://www.who.int/whosis/whostat/en/ (2008).

3. European Commission, White Paper: European transport policy for 2010: time to decide, Commission of the European Communities, Brussels (2001).

4. A. Charnes, W.W. Cooper, E. Rhodes, Measuring the efficiency of decision making units, European Journal of Operational Research, 2, pp. 429-444 (1978).

5. S. Malmquist, Index numbers and indifference surfaces. Trabajos de Estatistica, 4, pp. 209-242 (1953).

6. European Commission, EU energy and transport in figures, Commission of the European Communities, Brussels (2009).

7. R. Färe, S. Grosskopf, B. Lindgren, P. Roos, Productivity change in Swedish pharmacies 1980-1989: A nonparametric Malmquist approach, Journal of Productivity Analysis, 3, pp. 85-102 (1992).

8. B.K. Yörük, O. Zaim, Productivity growth in OECD countries: A comparison with Malmquist indices, Journal of Comparative Economics, 33, pp. 401-420 (2005).

9. M.R. Greer, Nothing focuses the mind on productivity quite like the fear of liquidation: Changes in airline productivity in the United States, 2000-2004, Transportation Research Part A, 42, pp. 414-426 (2008).

10. SafetyNet, State of the art report on risk and exposure data, D2.1, (2005). 